\title{
THE EFFECTS OF LEPTIN ADMINISTRATION ON RENAL FUNCTION IN SPONTANEOUSLY HYPERTENSIVE RATS
}

\author{
BRINNELL CASZO $^{1}$, AZDAYANTI MUSLIM ${ }^{2}$, ZANARIAH AWANG $^{2}$, EFFAT OMAR $^{2}$, EFFENDI IBRAHIM $^{2}$, \\ HARBINDARJEET SINGH ${ }^{2,3,4 *}$
}

${ }^{1}$ Faculty of Medicine and Defence Health, National Defence University of Malaysia, Kuala Lumpur, Malaysia. ${ }^{2}$ Faculty of Medicine, Universiti Teknologi MARA, Sg Buloh Campus, Sg Buloh, Selangor, Malaysia. ${ }^{3}$ IMMB, Faculty of Medicine, UiTM, Sg Buloh, Selangor, Malaysia. ${ }^{4}$ I-PPerForm, Universiti Teknologi MARA, Sg Buloh Campus, Sg Buloh, Selangor, Malaysia. Email: hjsingh@salam.uitm.edu.my

\author{
Received: 18 February 2016, Revised and Accepted: 29 September 2016
}

\section{ABSTRACT}

Objective: Elevated levels of leptin may be responsible directly for progression and severity of renal disease in obesity and hypertension. It may exert its effects by promoting fibrosis through the actions of transforming growth factor- $\beta 1$ (TGF- $\beta 1$ ) and the Smad pathway. This study determines the effect of leptin administration on the development of renal fibrosis in nonobese spontaneously hypertensive rats (SHRs).

Methods: Male SHRs, aged 12-14 weeks, were injected with either leptin ( $60 \mu \mathrm{g} / \mathrm{kg} / \mathrm{day}$ ) or saline (for the control group) subcutaneously daily for 42 days. At the end of the experimental period, animals were euthanized and their kidneys were removed. The right kidney was harvested for the determination of messenger ribonucleic acid (mRNA) expression of TGF- $\beta 1$, Smad2, Smad3, and bone morphogenic protein 7 (BMP7). The left kidneys were stored in neutral buffered $10 \%$ formalin until they were processed and stained with hematoxylin and eosin. Prepared slides were examined under light microscopy. 30 consecutive glomeruli were examined for the cell counts based on the number of nuclei seen and the total area of glomeruli.

Results: No significant difference was evident in renal function between control and leptin-treated rats. Cellularity and area of glomeruli were also not different between the two groups. mRNA expression of TGF- $\beta 1$, Smad2, and BMP7 were, however, higher in leptin-treated rats.

Conclusion: It appears that 6 weeks of leptin administration increases renal TGF- $\beta 1$ and Smad2 levels but with little morphological changes in the kidney. Whether the elevated BMP7 expression was responsible for lack of effect of leptin on renal morphological changes remains unclear

Keywords: Leptin, Renal function, Hypertension, Glomerulus, Transforming growth factor- $\beta 1$, Smad, Spontaneously hypertensive rats

(C) 2017 The Authors. Published by Innovare Academic Sciences Pvt Ltd. This is an open access article under the CC BY license (http://creativecommons. org/licenses/by/4. 0/) DOI: http://dx.doi.org/10.22159/ajpcr.2017.v10i1.11323

\section{INTRODUCTION}

Leptin is an adipokine with pleiotropic effects acting through leptin receptors in several body tissues. Apart from its well-established role in appetite and energy homeostasis, leptin is being increasingly implicated in several pathophysiologic processes although much remains to be confirmed. Leptin levels are usually elevated in obese individuals, and massively obese individuals are also known to have glomerulopathy including changes such as glomerulosclerosis, glomerulomegaly, and also marked by proteinuria [1-4]. The role of leptin in this, however, is unknown. Raised blood pressure is often also seen in obese individuals, which has been attributed to increased sympathetic nervous system activity, stimulated by elevated leptin [5]. Leptin administration to normotensive rats has been shown to increase blood pressure [6] Raised leptin level in obese hypertensive individuals could, therefore, worsen the complication of hypertension and might even be responsible for chronic kidney disease (CKD) and its progression to end-stage renal disease and renal failure $[7,8]$

Cytokines of the transforming growth factor- $\beta$ (TGF- $\beta$ ) family, particularly those regulating proliferation and growth of tissues, have been implicated in tissue fibrosis [9]. TGF- $\beta 1$, a member of this family of proteins, stimulates excessive production of extracellular matrix material via activation of Smad2 [7,10]. Structural and functional damage to tissues result in progression of the disease. Smad7, which is activated by Smad3, is inhibitory in nature [11]. TGF- $\beta 1$ might also be activated by Smad-independent pathways involving bone morphogenic protein 7 (BMP7) and offers the prospect of new therapeutic targets for treatment in CKD [9]. The involvement of leptin in obesity-related glomerulopathy (ORG) is unknown, and a link with leptin might describe a pathway that facilitates tissue damage and eventually CKD in conditions characterized by hyperleptinemia.

In addition to leptin, adipose tissue also releases numerous other adipokines, and it might not be possible to investigate the role of leptin in renal disease in an obese model. To study the role of leptin and raised blood pressure in glomerulosclerosis requires the use of a nonobese hypertensive animal model. This study, therefore, investigated the effects of exogenous leptin administration on glomerular function in spontaneously hypertensive rats (SHRs), which would be a novel pathway in the study of obesity/leptin-related glomerular disease pathogenesis. The central hypothesis of this study is that leptin has a direct role in the pathogenesis of kidney disease in hypertension.

\section{METHODS}

Male SHRs, aged 12-14 weeks, were given daily subcutaneous injections of either leptin (BioVision Milpitas, CA, USA) (60 $\mu \mathrm{g} / \mathrm{kg} / \mathrm{day}$; $\mathrm{n}=8$ ) or saline (vehicle; $\mathrm{n}=8$ ) for 42 days. All rats were housed singly in ventilated cages and maintained on a 12:12 hrs day-night cycle at the Laboratory Animal Care Unit, Universiti Teknologi MARA (UiTM) Sungai Buloh Campus. The study design was approved by the Animal Users and Care Committee of the Faculty of Medicine, (UiTM), Malaysia. They were fed standard rat chow and had free access to tap water. Blood pressure was measured once a week using a tail-cuff plethysmography (Kent Scientific Corporation, Torrington, CT, USA) [12]. Urine was collected over 24 hrs once a week in a metabolic cage and analyzed for urine electrolytes, urea, creatinine, and protein excretion. Blood was 
collected on the last day for the measurement of serum electrolytes, urea, creatinine, and albumin. On day 43 , animals were euthanized and kidneys were harvested and stored at $-80^{\circ} \mathrm{C}$ until analysis for determination TGF- $\beta 1 /$ Smad pathway expression.

Quantitative real-time polymerase chain reaction (RT-PCR) was used to determine messenger ribonucleic acid (mRNA) expression of TGF $\beta-1$, Smad2, 3 7, and BMP7 using the CYBR-green technique in a single-step reaction. RNA was extracted from the right kidney tissue using trizol reagent (Invitrogen, Life Technologies) and then subjected to the RTPCR assay. The ratio (i.e. fold-change) of gene expression levels in the leptin treatment groups to control rats was calculated relative to the housekeeping control genes - $\beta$-actin and glyceraldehyde 3 -phosphate dehydrogenase.

The other (left) kidneys were stored in neutral buffered $10 \%$ formalin until they were processed and stained with hematoxylin and eosin [13]. Prepared slides were analyzed by light microscopy. Digital images were captured using an imaging system (NIS-Element BR 3.1 image analysis system, Nikon, Tokyo, Japan). The tissue area was divided into three parts (upper, middle, and lower zone). 30 glomeruli in each part were measured consecutively for a count of total nuclei as well as total area $\left(\mu \mathrm{m}^{2}\right)$. Total number of nuclei was counted manually by counting hematoxylin stained areas inside the glomerulus. On the other hand, the total area was measured by tracing the outer limit of bowman's space using the image analysis software.

All data are expressed as mean \pm standard error of mean and comparisons between the means were made using the independent t-test, and a $\mathrm{p}<0.05$ was accepted as statistically significant.

\section{RESULTS}

All animals had a steady increase in body weight throughout the study period, and neither of the groups differed in body weight both at the start and at the end of the study period (Table 1).

Systolic blood pressure was not significantly different between the two groups either at the beginning or at the end of the study (Table 2).

Tests of renal function including urine output, creatinine clearance,

Table 1: Body weight (g) of control and leptin-treated rats for 42 days treatment

\begin{tabular}{lll}
\hline Group & Body weight g Day 0 & Body weight in g Day 42 \\
\hline Control & $254 \pm 8.09$ & $291 \pm 8.87$ \\
Leptin & $252 \pm 3.09$ & $277 \pm 6.46$ \\
\hline
\end{tabular}

Table 2: Mean systolic blood pressure of control and leptin-treated rats for 42 days treatment

\begin{tabular}{lll}
\hline Group & \multicolumn{2}{l}{ Blood pressure } \\
\cline { 2 - 3 } & Day 0 & Day 42 \\
\hline Control (mmHg) & $180 \pm 4.07$ & $184 \pm 5.38$ \\
Leptin (mmHg) & $175 \pm 3.73$ & $189 \pm 4.56$ \\
\hline
\end{tabular}

mmHg: Millimeters of mercury; conventional unit for measuring blood pressure total protein, and albumin, and urine electrolytes were not significantly different between the two groups on day 42 of the study (Table 3).

Histopathology of the kidney revealed that comparable number of nuclei inside 90 consecutive glomeruli as well as area of the glomeruli (Table 4)

Gene expression of TGF- $\beta 1$, Smad2, and BMP7 was elevated two-fold, and Smad7 and Smad3 levels were decreased by $50 \%$ in the leptintreated groups.

\section{DISCUSSION}

The study was designed to mimic hypertension without obesity. Leptin was administered to create transient hyperleptinemia daily for 42 days to elucidate the peripheral effects of leptin. Since obesity is a contributing factor to poor outcome of renal function in hypertensive, it might be possible that leptin contributes to the pathogenesis of these disorders. SHR was selected as the experimental model as it is an accepted animal model of essential hypertension [14]. This model was especially suitable to the proposed experimental design since these animals develop hypertension by genetic mechanisms [15] and do not express the obese phenotype.

At the dose administered in this study ( $60 \mu \mathrm{g} / \mathrm{kg} /$ day) for 42 days, leptin appeared to have no effect on blood pressure and the progression of renal dysfunction in the SHR. All parameters of renal function measured showed that treated animals were no worse than control animals. Proteinuria, albuminuria was present in both groups, creatinine clearance (to approximate glomerular filtration rate) and rate of excretion of electrolytes (sodium and potassium) in the urine were not different between the two groups after 42 days. These findings suggest a lack of progression of renal disease in the leptin administered rats. It might be that at the dose of leptin administered might not be adequate to induce significant changes in kidney function in the treatment group when compared to that of the controls or it could be due to the duration of the leptin administration might be insufficient and that a longer duration might be required. SHR usually develops proteinuria only after the $30^{\text {th }}$ week of age [16]. In our study, we predicted an earlier progression (20 weeks) to renal dysfunction based on our previous study on the peripheral effects of leptin on hypertension in normal Sprague-Dawley rats [6]. The unresponsiveness to leptin in SHR could also be due to the development of selective leptin resistance due to the 42 days administration of leptin. Kidney tissues demonstrate a high concentration of leptin receptors, especially the soluble form of the leptin receptor and they may be adversely affected by elevated leptin level.

Results of the histopathological studies showed no statistically significant differences in glomerular area and number of nuclei, although the area and the number of nuclei were slightly, albeit nonsignificantly, lower in leptin-treated rats (Table 4). This might indicate that glomerular volume was reduced by treatment with leptin, which seems contrary to findings reported in ORG in the literature where patients with ORG had larger glomeruli than those with idiopathic disease [1]. Medaka fish fed on a high-fat diet were found to have larger glomeruli than those in controls fed a normal diet [17]. The reason for the difference is unclear but it might be that the animals in this study were not obese and it is possible that some other factors in

Table 3: Renal parameters of control and leptin-treated rats on day 42 of treatment

\begin{tabular}{|c|c|c|c|c|c|c|}
\hline \multirow[t]{2}{*}{ Groups } & \multirow{2}{*}{$\begin{array}{l}\text { Creatinine clearance } \\
(\mu \mathrm{l} / \mathrm{min})\end{array}$} & \multirow{2}{*}{$\begin{array}{l}\text { Urine output } \\
\text { (ml/day) }\end{array}$} & \multicolumn{2}{|l|}{ Urine } & \multicolumn{2}{|l|}{ Urinary } \\
\hline & & & Albumin (g/L) & Total protein $(\mathrm{g} / \mathrm{L})$ & $\begin{array}{l}\text { Sodium excretion } \\
\text { (umol/min) }\end{array}$ & $\begin{array}{l}\text { Potassium excretion } \\
\text { (umol/min) }\end{array}$ \\
\hline Control & $799.6 \pm 84.3$ & $9 \pm 1.20$ & $0.98 \pm 0.18$ & $3.40 \pm 0.45$ & $0.73 \pm 0.13$ & $1.04 \pm 0.17$ \\
\hline Leptin & $716.8 \pm 51.8$ & $10 \pm 1.29$ & $0.70 \pm 0.25$ & $2.24 \pm 0.35$ & $0.56 \pm 0.10$ & $0.65 \pm 0.10$ \\
\hline
\end{tabular}


Table 4: Total number of nuclei inside a glomerulus and area of glomeruli in control and leptin-treated rat kidneys after 42 days of treatment

\begin{tabular}{lll}
\hline Group & $\begin{array}{l}\text { Mean number of nuclei } \\
\text { per glomerulus }\end{array}$ & Area of glomeruli $\left(\boldsymbol{\mu m}^{2}\right)$ \\
\hline Control & $4297 \pm 169$ & $653725.1 \pm 24422.0$ \\
Leptin & $4012 \pm 186$ & $613212.2 \pm 21114.0$ \\
\hline
\end{tabular}

obesity might be involved. In addition, it also suggests that leptin might not be directly involved in the hypertrophy of the glomeruli or obesityrelated glomerulopathy.

While little difference was evident in renal function and histology between control and leptin-treated groups, TGF- $\beta 1$, Smad2, and BMP7 mRNA expressions were higher, whereas Smad3 and Smad7 levels were lower in leptin-treated rats. TGF- $\beta 1$ is believed to be the link between leptin and the development of glomerulosclerosis [18]. Transgenic mice with higher levels of TGF- $\beta 1$ in the plasma had progressive glomerulosclerosis [19]. TGF- $\beta 1$ expression was also higher, along with changes in mesangium and glomerular basement membrane, in $\mathrm{db} / \mathrm{db}$ mice similar to changes seen in nephropathy of Type 2 diabetes mellitus [20]. Similar evidence has also been reported from human studies where increased TGF- $\beta 1$ is associated with a higher risk for liver cirrhosis $[21,22]$. TGF- $\beta 1$ effects are mediated through TGF- $\beta 1$ Type II receptors and the Smad pathway. Activation leads to the formation of Smad2/3 complex, which translocates to the nucleus and triggers target gene transcription. Smad2 expression was also significantly higher in leptin-treated rats. The exact mechanism responsible for leptinstimulated increase in TGF- $\beta 1$ expression is unclear, but evidence from studies on nonalcoholic steatohepatitis suggests that leptin-mediated oxidative stress might be responsible for the elevated TGF- $\beta 1$ levels [23]. Decreased Smad7 might be associated with increased renal fibrosis as Smad7 knockout mice been found to show a more severe progression of renal dysfunction and renal fibrosis than wild-type control animals, suggesting a protective role for Smad7 in renal fibrosis [21]. BMP7 activation occurs by pathways independent of TGF- $\beta 1$, and it is possible leptin administration simultaneously triggered BMP7 expression. BMP7 is a major inhibitor of fibrosis [24]. It might explain why there is a lack of worsening of renal dysfunction and histological evidence of renal dysfunction in the leptin-treated animals.

\section{CONCLUSION}

Administration of leptin at a dose of $60 \mu \mathrm{g} /$ day for 42 days did not affect kidney function and histopathology in SHR. However, it seems to have increased the expression of TGF- $\beta 1$, Smad2, and BMP7. Whether the elevated BMP7 expression may be responsible for lack of effect of leptin on renal function is a question that remains to be answered. Slight higher doses of leptin and perhaps a longer duration of administration could help further clarify the role of leptin in glomerular sclerosis.

\section{ACKNOWLEDGMENT}

The authors thank all the technical staff at the Institute of Medical and Molecular Biology, Laboratory Animal Care Unit, Faculty of Medicine, UiTM and Research Laboratory, UPNM, for their assistance. This research was funded by the Ministry of Higher Education, Malaysia, under the RAG Scheme (600-RMI/RAGS 5/3 [87/2013], RAGS/2012/ UPNM/SKK01/1), and (MSH) (100-RMI/PRI 16/6/2 [71/2010]).

\section{REFERENCES}

1. Kambham N, Markowitz GS, Valeri AM, Lin J, D'Agati VD. Obesity-related glomerulopathy: An emerging epidemic. Kidney Int
2001;59(4):1498-509.

2. Verani RR. Obesity-associated focal segmental glomerulosclerosis Pathological features of the lesions and relationship with cardiomegaly and hyperlipidemia. Am J Kidney Dis 1992;20(6):629-34.

3. Jennette JC, Charles L, Grubb W. Glomerulomegaly and focal segmental glomerulosclerosis associated with obesity and sleep-apnea syndrome. Am J Kidney Dis 1987;10(6):470-2.

4. Kasiske BL, Crosson JT. Renal disease in patients with massive obesity. Arch Intern Med 1986;146(6):1105-9.

5. Carlyle M, Jones OB, Kuo JJ, Hall JE. Chronic cardiovascular and renal actions of leptin: Role of adrenergic activity. Hypertension 2002;39:496-501.

6. Farhana K, Effendi I, Caszo B, Satar NA, Singh HJ. Exercise prevents leptin-induced increase in blood pressure in Sprague-Dawley rats. J Physiol Biochem 2014;70(2):417-23.

7. Tan CK, Chong HC, Tan EH, Tan NS. Getting 'Smad' about obesity and diabetes. Nutr Diabetes 2012;2:e29.

8. Tsuboi N, Koike K, Hirano K, Utsunomiya Y, Kawamura T, Hosoya T. Clinical features and long-term renal outcomes of Japanese patients with obesity-related glomerulopathy. Clin Exp Nephrol 2013;17(3):379-85.

9. Lan HY. Diverse roles of TGF- $\beta /$ Smads in renal fibrosis and inflammation. Int J Biol Sci 2011;7(7):1056-67.

10. Flanders KC. Smad3 as a mediator of the fibrotic response. Int J Exp Pathol 2004;85(2):47-64.

11. Chen BL, Peng J, Li QF, Yang M, Wang Y, Chen W. Exogenous bone morphogenetic protein-7 reduces hepatic fibrosis in Schistosoma japonicum-infected mice via transforming growth factor- $\beta / \mathrm{Smad}$ signaling. World J Gastroenterol 2013;19(9):1405-15.

12. Caszo B, Awang Z, Gnanou J, Singh HJ. The presence of a littermate during measurement of blood pressure reduces the acclimatization time in conscious naïve rats. Asian J Pharm Clin Res 2015;8(2):151-3.

13. Kamang R, Fondjo AF, Oyono JE. Effect of methanolic fraction of Kalanchoe crenata on renal morphophysiology in adriamycin-induced impaired kidney in rats. Int J Pharm Pharm Sci 2015;7(2):86-93.

14. Okamoto K, Aoki K. Development of a strain of spontaneously hypertensive rats. Jpn Circ J 1963;27:282-93.

15. Ely D, Boehme S, Dunphy G, Hart M, Chiarappa F, Miller B, et al. The Sry3 Y chromosome locus elevates blood pressure and reninangiotensin system indexes. Gend Med 2011;8(2):126-38.

16. Feld LG, Van Liew JB, Brentjens JR, Boylan JW. Renal lesions and proteinuria in the spontaneously hypertensive rat made normotensive by treatment. Kidney Int 1981;20(5):606-14.

17. Ichimura K, Kawashima Y, Nakamura T, Powell R, Hidoh Y, Terai S, et al. Medaka fish, Oryzias latipes, as a model for human obesity-related glomerulopathy. Biochem Biophys Res Commun 2013;431(4):712-7.

18. Wolf G, Hamann A, Han DC, Helmchen U, Thaiss F, Ziyadeh FN, et al. Leptin stimulates proliferation and TGF-beta expression in renal glomerular endothelial cells: Potential role in glomerulosclerosis [seecomments]. Kidney Int 1999;56(3):860-72.

19. Kopp JB, Factor VM, Mozes M, Nagy P, Sanderson N, Böttinger EP, et al. Transgenic mice with increased plasma levels of TGF-beta 1 develop progressive renal disease. Lab Invest 1996;74(6):991-1003.

20. Siew-Keah L, Sundaram A, Sirajudeen KN, Zakaria R, Singh HJ. Effect of melatonin supplementation and cross-fostering on renal glutathione system and development of hypertension in spontaneously hypertensive rats. J Physiol Biochem 2014;70(1):73-9.

21. Liu GX, Li YQ, Huang XR, Wei L, Chen HY, Shi YJ, et al. Disruption of Smad7 promotes ANG II-mediated renal inflammation and fibrosis via Sp1-TGF-ß/Smad3-NF. $\kappa B-d e p e n d e n t$ mechanisms in mice. PLoS One 2013;8(1):e53573

22. Kandavelu S, Somasundaram PC, John B, Rajendran R. Proinflammatory cytokines elicit inflammatory response in blood leukocytes of post dialytic chronic renal patients through heme oxygenase-1 activation. Int J Pharm Pharm Sci 2014;6(9):111-5.

23. Dattaroy D, Pourhoseini S, Das S, Alhasson F, Seth RK, Nagarkatti M, et al. Micro-RNA 21 inhibition of SMAD 7 enhances fibrogenesis via leptin mediated NADPH oxidase in experimental and human nonalcoholic steatohepatitis. Am J Physiol Gastrointest Liver Physiol 2015;308(4):G298-312.

24. Anbarasi G, Kumar KS, Narmadha P, Srinivasan N. Effect of vitamin $\mathrm{C}$ on mRNA expression of BMPs during fracture healing in the femur callus of Sprague-Dawley female rats. Int J Pharm Pharm Sci 2014;6(8):206-18. 